Int. J. Electrochem. Sci., 14 (2019) $4144-4160$

\title{
Electrochemical Behavior of 2205 Duplex Stainless Steel in a Chloride-Thiosulfate Environment
}

\author{
Jiantao Zhang ${ }^{1}$, Xiaojun $\mathrm{Hu}^{l, *}$, Ping Lin $^{2}$, and Kuochih Chou ${ }^{1}$ \\ ${ }^{1}$ State Key Laboratory of Advanced Metallurgy, University of Science and Technology Beijing, \\ Beijing 100083, P.R. China \\ ${ }^{2}$ Ruipu Technology Group Co, Ltd, Lishui, Zhejiang, 323903, P.R. China \\ *E-mail: huxiaojun@ustb.edu.cn
}

doi: $10.20964 / 2019.05 .06$

Received: 6 January 2019 / Accepted: 12 February 2019 / Published: 10 April 2019

\begin{abstract}
The electrochemical behavior of 2205 duplex stainless steel in chloride-thiosulfate environment was investigated by various methods: potentiodynamic polarization, electrochemical impedance spectroscopy (EIS), and Mott-Schottky measurements. The chemical composition of the passive films was analyzed by X-ray photoelectron spectroscopy (XPS). The composition of the gases produced during the corrosion process was detected by a mass spectrometer. The results indicated that $\mathrm{S}_{2} \mathrm{O}_{3}^{2-}$ had a synergistic and detrimental effect on passive film breakdown and made it easier for $\mathrm{Cl}^{-}$to initiate pitting by reducing to hydrogen sulfide which catalyzed the anodic dissolution. The selective dissolution of the ferrite phase was investigated on 2205 duplex stainless steel. The $\mathrm{Cl}^{-}$and $\mathrm{S}_{2} \mathrm{O}_{3}^{2-}$ slightly deteriorated the passive films in the passive region at high anodic potentials, and $\mathrm{S}_{2} \mathrm{O}_{3}^{2-}$ facilitated the oxidation of $\mathrm{Cr}(\mathrm{III})$ to $\mathrm{Cr}(\mathrm{VI})$. The capacitance and XPS results revealed that the oxide films on 2205 duplex stainless steel consisted mainly of $\mathrm{Cr}$ oxide and Fe oxide, and in different passive regions, they exhibit different electrochemical and semiconductor properties.
\end{abstract}

Keywords: 2205 duplex stainless steel, electrochemical behavior, chloride-thiosulfate, passive film.

\section{FULL TEXT}

(C) 2019 The Authors. Published by ESG (www.electrochemsci.org). This article is an open access article distributed under the terms and conditions of the Creative Commons Attribution license (http://creativecommons.org/licenses/by/4.0/). 